\section{AB1399-HPR FOOT AND ANKLE ASSESSMENT IN PATIENTS WITH DIFFERENT GRADES OF KNEE OSTEOARTHRITIS}

KARAPINAR MERVE ${ }^{1}$, Ferdi Baskurt ${ }^{1}$, Zeliha Baskurt ${ }^{1}$, Meric Unal ${ }^{2} .{ }^{1}$ Faculty of Health Science, Physiotherapy and Rehabilitation, ISPARTA, Turkey, ${ }^{2}$ Faculty of Medicine, Sports Medicine, ISPARTA, Turkey

Background: Foot and ankle profile has long been considered to contribute to the development of knee osteoarthritis $(\mathrm{OA})$. It may alter the mechanical alignment and dynamic function of the lower limb especially knee functions. It is important to determined compensatory changes in the foot and ankle posture in patients with different grades of knee osteoarthritis. Because it may help in understanding the role of foot orthoses, footwear modifications or treatment strategies on alignment and function of knee

Objectives: This present study was designed to assess the changes in foot and ankle profile among different grades of knee OA.

Methods: Patients were assessed with physical examination including foot and knee specifically and anteroposterior and lateral direct radiographies. All patients were divided into four groups for medial compartment OA severity by using the Kellgren-Lawrence grading system of knee $\mathrm{OA}$ on weight bearing knee radiographies. The Western Ontario and Mc Master University Osteoarthritis Index (WOMAC) questionnaire was performed to assess pain and the functional status of the patients. Structural foot profile was assessed by the Foot Posture Index (FPI) system and American Orthopaedic Foot and Ankle Society (AOFAS) anklehindfoot and midfoot scales.

Results: The study included forty-four patients with mean age 57.1212.2 years. In terms of severity of knee OA groups; percentages for grade 0 $1,2,3$ and 4 were $25 \%, 22.7 \%, 25 \%, 27.2 \%$ respectively. In the grade 4 and 3 with knee OA; WOMAC total score, pain and function subscale scores were higher $(\mathrm{p}<0.001)$. Besides, foot pronation was also increased as the severity of osteoarthritis increased. In the grade $0-1$ and grade 2; AOFAS hindfoot and midfoot scores were higher $(p<0.001)$ compere to severe OA (grade 3 and grade 4).

Conclusion: The study indicates that differences of the severity of $O A$ have influence on the foot and ankle profile to different degrees. Therefore, it is clinically important to give appropriate orthotics advice or treatment to patients with different degrees of $\mathrm{OA}$ to correct the pronation of foot to different degrees.

\section{REFERENCES}

[1] Saito, I., Okada, K., Wakasa, M., Abe, H., \& Saito, A. (2018). Foot pressure pattern, hindfoot deformities, and their associations with foot pain in individuals with advanced medial knee osteoarthritis. Gait \& posture, 59, 83-88.

\begin{tabular}{|c|c|c|c|c|c|}
\hline & \multicolumn{4}{|c|}{ K-L Scores } & p \\
\hline Paremeter & $0-1$ (n: 11) & $2(n: 10)$ & 3 (n: 11) & $4(n: 12)$ & \\
\hline Age, years * & 56.97 .6 & 52.37 .7 & 62.68 .2 & 58.28 .5 & 0.37 \\
\hline Female, $\mathrm{n}(\%)$ & $6(54.5)$ & $6(60)$ & $6(54.5)$ & $7(58.3)$ & 0.16 \\
\hline Height, $(\mathrm{cm})^{*}$ & 164.70 .7 & 165.40 .11 & 162.20 .08 & 163.41 .1 & 0.25 \\
\hline Body weight $(\mathrm{kg})^{*}$ & 80.310 .3 & 82.216 .9 & 70.711 .1 & 78.915 .1 & 0.14 \\
\hline $\begin{array}{l}\text { Body mass index } \\
\left(\mathrm{kg} / \mathrm{m}^{2}\right)^{*}\end{array}$ & 29.52 .8 & 29.94 .1 & 31.262 & 29.44 .7 & 0.37 \\
\hline WOMAC ** & $12(7-15)$ & $14(12.5-21))$ & $31(14-40)$ & $33(28-45)$ & $0.001^{\delta}$ \\
\hline AOFAS-hindfoot** & $80(74-88)$ & $85(69-91.25)$ & $55(48-74)$ & $59.5(55-66)$ & $0.001^{\delta}$ \\
\hline AOFAS-midfoot ** & $88(72-91)$ & $85(79-87.75)$ & $57(52-79)$ & $59(54-66.5)$ & $0.03^{\delta}$ \\
\hline
\end{tabular}

*. Values are reported as mean SD

**;Values are reported as median(IQR)

;; Significant at $\mathrm{p}<0.05$

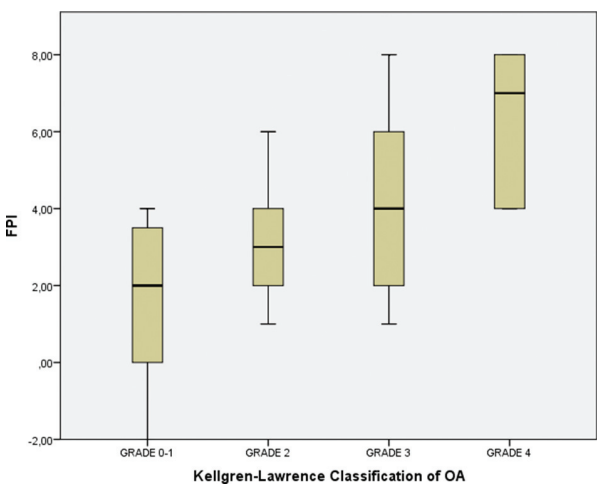

Disclosure of Interests: None declared

DOI: 10.1136/annrheumdis-2019-eular.4718

\section{AB1400-HPR EFFECT OF FOOT PAIN ON FUNCTION, FEAR OF FALLING AND QUALITY OF LIFE IN ELDERLY PEOPLE WITH KNEE OSTEOARTHRITIS}

Merve Karapinarr ${ }^{1}$, Zeliha Baskurt ${ }^{1}$, Ferdi Baskurt ${ }^{1}$, Meric Unal ${ }^{2}$. ${ }^{1}$ Faculty of Health Science, Physiotherapy and Rehabilitation, ISPARTA, Turkey; ${ }^{2}$ Faculty of Medicine, Sports Medicine, ISPARTA, Turkey

Background: Knee osteoarthritis $(O A)$ is a frequently seen disorder affecting approximately $30 \%$ of people over 65 years. Foot pain often defined as pain in the foot and/or ankle, is also very common among older people. This problem may effect on mobility, falling risk and quality of life in elderly patient with knee OA. But there is no study investigate to effect of foot pain on the function, fear of falling and quality of life in elderly people with knee $O A$.

Objectives: Concurrent foot pain in elderly people with knee OA may be the potential to further increase disability and immobility.

Methods: Fifty patients with radiographic and clinic evidence of tibiofemoral OA (Kellgren-Lawrence score 2) were included. The Western Ontario and Mc Master University Osteoarthritis Index (WOMAC) questionnaire was used to assess pain and the functional status of the all patients. Foot pain was measured with the Manchester-Oxford Foot Questionnaire (MOFQ) and $100 \mathrm{~mm}$ Visual Analog scale (VAS). Patients were divided into two groups (with foot pain and without foot pain) based on patient-reported pain using VAS and MOFQ. Two groups with knee OA were compared for difference in patient functional assessment quality of life and fear of falling. To evaluate physical function measured by using the Time up Go Test (TUG), health related quality of life (HRQOL) measured by using EuroQOL five dimensions (EQ-5D) questionnaire and fear of falling measured by using Tinetti Falls Efficacy Scale.

Results: Within our sample of older adults with knee OA, $52 \%$ had foot pain $(26 / 50)$. VAS scores of patients with knee OA and without foot pain were zero. Compared to the group without foot pain of similar age $(n=$ $24)$, those with foot pain had reduced quality of life and profound mobility limitations and more fear of falling $(p<0.001)$.

Conclusion: Older adults with knee $\mathrm{OA}$ and also foot pain have pronounced mobility limitations and increased fear of falling and also these are associated with a marked reduction in HRQOL. Future prospective research is required to build on this study.

\section{REFERENCES}

[1] Stubbs, B., Binnekade, T., Eggermont, L., Sepehry, A. A., Patchay, S., \& Schofield, P. (2014). Pain and the risk for falls in community-dwelling older adults: systematic review and meta-analysis. Archives of physical medicine and rehabilitation, 95(1), 175-187

[2] Chen, J., Devine, A., Dick, I. M., Dhaliwal, S. S., \& Prince, R. L. (2003). Prevalence of lower extremity pain and its association with functionality and quality of life in elderly women in Australia. The Journal of Rheumatology, 30(12), 2689-2693.

\begin{tabular}{lccc}
\hline Variable & $\begin{array}{c}\text { 1.Group with Foot } \\
\text { Pain }(\mathbf{n = 2 6 )}\end{array}$ & $\begin{array}{c}\text { 2.Group without Foot } \\
\text { Pain }(\mathbf{n = 2 4})\end{array}$ & $\begin{array}{c}\boldsymbol{p} \\
\text { value }\end{array}$ \\
\hline Age (years, SD) & $74.4(8.5)$ & $76.3(7.8)$ & 0.19 \\
Female $\mathrm{n}(\%)$ & $16(61.5)$ & $16(66.6)$ & 0.24 \\
Body Mass Index $\left(\mathrm{kg} / \mathrm{m}^{2}, \mathrm{SD}\right)$ & $29.5(6.8)$ & $29.9(7.1)$ & 0.35 \\
Number of comorbidities (SD) & $3.8(2.3)$ & $3.1(1.2)$ & 0.07 \\
& & & \\
MOFQ (SD) & $54.2(12.4)$ & $4(1.2)$ & $0.001^{\text {* }}$ \\
Time Up Go Score (sec, SD) & $32.84(19.3)$ & $19.8(6.03)$ & $0.001^{*}$ \\
HRQOL (SD) & $69.5(19.5)$ & $43.2(13.7)$ & $0.001^{\text {* }}$ \\
Fear of Falling (SD) & $76.1(17.8)$ & $40.2(14.9)$ & $0.040^{*}$ \\
MOFQ; Manchester-Oxford & & & \\
Foot Questionnaire & & & \\
HRQOL; Health Related Quality & & & \\
of Life & & & \\
SD; Standard Deviation; & & & \\
*Significant at $\mathrm{p}<0.05$ & & & \\
\hline
\end{tabular}

Disclosure of Interests: None declared

DOI: 10.1136/annrheumdis-2019-eular.7134 